\title{
Understanding Trust within Online Discussion Boards: Trust Formation in the Absence of Reputation Systems
}

\author{
Sarah Talboom and Jo Pierson \\ iMinds - SMIT - VUB, Brussels, Belgium \\ \{sarah.talboom, jo.pierson\} @vub.ac.be
}

\begin{abstract}
Trust plays an important role when it comes to sharing and picking up information on the Internet. Even more so when advice is being exchanged and decisions are being made based on what at first sight seems to be interpersonal communication between people who do not know each other. Research concerned with the role of trust in making an assessment of online user-generated information, often focuses on online reputation systems rather than on the way individuals try to evaluate peer recommendations themselves. In this paper the attention goes out to the construction of trust when people are looking for advice and know-how via online textual discussion boards. The study offers an understanding of online trust by defining the concept of trust, by formulating a trust typology - based on both the object of trust and the stages within a trust relationship - and by identifying trust antecedents. All this while keeping a close eye on the context of online forums and their users.
\end{abstract}

Keywords: Online trust, trust, online discussion platforms, information search, advice.

\section{Introduction}

The study starts from the idea that an online community can play a significant role when it comes to making important individual decisions. When people are looking for information - such as how-to knowledge or pre-buy advice -, they can use User Generated Content (UGC). This way the information search process is becoming a social event, where Internet users can be acknowledged valuable information sources. This is also how Facebook is framing their 'Graph Search' function, namely by socializing search, although in their case making use of friends. ${ }^{1}$ UGC is often seen as an important support tool for an assertive, self-reliant and informed Internet user, since it gave people the opportunity to create and share content themselves. Yet because of its open publication principle, online users are being confronted with information that has not been verified by traditional gatekeepers. Anyone with the right skills and hardware can publish content online. Combining this finding with the fact that many online contributions cannot be directly linked to a particular person (in comparison to the Facebook example) raises some questions concerning trust.

\footnotetext{
${ }^{1}$ https : / /www. facebook.com/about/graphsearch 
Before people will share and pick up online information, they must experience some level of trust [1][2][3]. However, literature shows that in a traditional situation, trust will emerge slowly during the process where people get to know each other ([4] based on the work of Blomqvist). Identity, reputation and experience are important antecedents that are not always that easy to deduce online. Online communication does not always offer enough knowledge on the skills and capacities of online information providers. This insecurity about the identity of others, combined with the lack of a common interaction history, makes trust development less evident. However, when users succeed in building their own identity and get an understanding of the identity of others, they are much more able to anticipate on the answers of others and thus to build trust (Henderson \& Gilding, 2004 and Tanis \& Postmes, 2005 as mentioned in [5]). Within this paper we use a more sociological approach to trust with a focus on people and how they behave individually as well as collectively within a specific online context: the online bulletin board.

When looking at research concerning online trust, we often find links with ecommerce [6][7] - where a high degree of trust in an online retailer would have a positive effect on sales figures. Although we could - at first sight - make a leap from e-commerce to our own research theme, it seems that many studies focus on electronic recommendation agents rather than on peer consumers as recommenders [8]. Also the importance of trust when releasing personal data online is increasingly being studied [9]. The link between online interpersonal communication and trust is less often discussed in scientific research, as well as the role of trust for selecting and evaluating information sources [2]. Exceptions are the importance of trust for the cooperation within virtual teams [10] and the use of online user-generated health information by patients [11]. This last domain often emphasizes the actual reliability and accuracy of the disseminated information. Within this study however, the attention goes out to the way trust is build in a (semi) anonymous online environment between people, irrespective of the actual accuracy of the information.

Within both public debate and scientific research, a lot of attention is often given to interpersonal communication via social media like Facebook and Twitter. Yet a person who wishes to gather information about various topics does not necessarily have to turn to people within his own network. The reason why we focus on online textual platforms has to do with the problematic nature of such environments. Within discussion boards, information is exchanged and decisions are made based on what at first sight seems to be interpersonal communication between people who do not know each other (that well). This contrasts highly with social media platforms, where it is generally assumed that you use your own personal details. In online discussion groups, people should not even have real conversations with other members; they can get started by just reading the conversations of others. An online forum, based solely on text, lacks some clues that are present in physical contexts or in online surroundings where you meet up people you know offline. This lack of cues is further emphasized by the fact that conversations do not occur synchronously. Finally, research has also shown that text-based conversations create a greater sense of social distance and that feelings of trust would build up slowly [12]. 
Within this paper, we focus on the construction of trust when people are looking for both implicit and explicit know-how within a mainly textual online environment: What is the role of this concept when picking up information and sharing knowledge? Which factors ensure or prevent trust to emerge online? The study offers an understanding of trust in online discussion forums by defining the concept of trust, formulating a trust typology and identifying trust antecedents while keeping a close eye on the context in which trust occurs.

\section{The Concept of Trust}

Research on the concept of trust has been around for over 60 years. Various disciplines sought to understand trust from different perspectives [13]. As a result, there exists a multitude of conceptualizations depending on the context and the domain in which the concept is used. McEvily, Weber, Bicchieri and Ho [14] state that despite this heterogeneity between different definitions, some common elements can still be identified. These common elements are important conditions for trust to emerge and are therefore key elements in defining the concept.

A first key element is interdependence [14][15]. When involved in a trusting relationship, at least one party chooses to depend on the other party [16]. If you want to reach a certain goal for which you need to depend on [e.g. the advice of] another person, than the responsibility to actually achieve this goal is partly under control of someone else. The individual who is willing to be dependent - the trustor - bases his reliance on a positive expectation [15][17]. You are only willing to rely upon a specific person because you expect that person whom you trust - the trustee - to be competent, reliable and honest, which ensures that the set goals will be met. Yet, you are never $100 \%$ sure regarding the outcome of this trust: you take a certain risk when you put your trust in someone. According to leading authors such as Luhmann [18], Gambetta [19] and Sztompka [20], risk is unavoidable when it comes to the development of trust. Without risk there is no need for trust. The same goes for insecurity or ignorance [14][17][20][21]. Trust is only necessary when absolute knowledge is missing, which makes it not possible to make an accurate estimation of the result of this trusting behavior. Incomplete knowledge nourishes insecurity and increases feelings of risk and thus the need for trust ([21] based on the work of Simmel \& Gambetta). When these feelings of risk are too high, people will not proceed to trusting and risk taking behavior [22]. This shows that both trust and risk are strongly related to action. In one respect, there is no risk without action, risks are taken and subjected [18][20][21]. Yet on the other hand, a lack of trust will ensure that certain behavior will not occur [21]. Because of this interdependence and since you are never sure of the desired outcome, you put yourself in a vulnerable position [14][15]. It is quite possible that the trustee is not able or even not willing to provide you with adequate advice, which means that your goal will not be reached. Trust is therefore only necessary when the outcome could also turn out bad [23].

An often-mentioned definition that combines these key concepts interdependence, expectations, risk, insecurity, action and vulnerability, is the one from Mayer, Davis 
and Schoorman [22]. They see trust as 'the willingness of a party to be vulnerable to the actions of another party, based on the expectation that the other will perform a particular action important to the trustor, irrespective of the ability to monitor or control that other party'. The last part of this definition - irrespective of the ability to monitor or control - refers to vulnerability, risk and uncertainty. '[People] have a certain degree of freedom to disappoint our expectations' [19]; therefore we have no guarantee that our expectations will be met. You cannot check whether the person whose advice you take into consideration, is in the right position to give proper and sincere advice. Accepting the advice of people you have never met before can therefore clearly be seen as a manifestation of trust.

\section{The Context of Trust}

Before we go deeper into the different typologies and antecedents of trust, it is important to emphasize the context in which trust will [or will not] occur.

First of all the focus is on the use of a text-only discussion forum for the exchange of ideas and support, and the gathering of information before a given action will be taken. This exchange of information situates itself at both the level of explicit and tacit [24] or organic knowledge - knowledge based on everyday personal experiences [25]. On the other hand, attention is paid to the idea of trust in the opinions of people you do not know [that well]. Traditionally an information seeker will try to make an assessment of the knowledge, skills and veracity of the information provider, in order to decide whether or not to grant trust. However, if you are looking for advice or experience of others, it is not unrealistic that your search will be accompanied by feelings of insecurity and risk. The amount of online information is enormous, different users contain different levels of expertise [26] and not all the information that you encounter is usable, reliable or correct. An online world is traditionally more muted than offline social spaces. According to Fisher [27], people do have some cues, but these are more difficult to find. Additionally, contributions on discussion platforms are all displayed in a similar way. This may create some kind of leveling effect where all authors are considered equally credible (Burbulus, 1998 as mentioned in [28]). The fact that you do not see [a visual] difference between various online contributions emphasizes again the risk for the information seeker in deciding which experts to consult. Many Web 2.0 and 3.0 applications try to solve this by 'calculating' trust based on information from previous interactions. By ascribing more weight to the contributions of trustworthy people, platforms try to use trust as a kind of filter. This way people - who do not have a clear link with each other - can still make an estimation of the quality of the information and thus decide to proceed to trusting behavior [29]. It is important to emphasize that we are not looking for a solution for this difficult relationship between trust and 'text-only platforms' - it is clear that this already exists in the form of the abovementioned trust and reputation systems. We merely want to understand how and based on which aspects trust is being shaped within this type of environment. How do you assess whether your source has the necessary knowledge and skills? 
Overall, two main issues are often raised when it comes to trust within textual online communities. First of all you have the fact that the exchange of conversations takes place between people who will probably never meet physically. Grasping the identity of your discussion partner becomes a difficult assignment, especially when looking at the anonymous nature of some exchanges [29]. Furthermore, people looking for advice based on online discussion forums often lack experience with the trustee. This while past experience, reputation and the duration of a relationship, along with [inter alia] insight into skills and competences are important antecedents of trust [21][30].

'In the digital world we are socially blind [...]' [31]. The visual hints shared within an online discussion forum are different than those shared in a traditional conversation. Besides the absence of some important physical, verbal and behavioral cues, people also miss out on identity indications such as age, education, lifestyle and status. Online cues would not be as rich as their face-to-face counterparts [32]. However, people tend to trust others when they are similar to themselves [20][29][33][34], so cues do play an important role. Question is whether this similarity between people really takes shape on the basis of traditional cues and individual characteristics of members. Furthermore some new cues emerge online. Elements such as writing style, a nickname, the intensity of contributions or sharing personal information can shed light on the identity of forum members. The ease, with which these new signals can be picked up, seems strongly related to the type of user. According to Blanchard, Welbourne and Boughton [5]: 'It simply takes a good deal more time and communication effort for an appropriate amount of cues to be accumulated in computer-mediated-communication'. In addition, Fisher [27] states that there are few signs aimed at new readers. This is especially problematic when a user just quickly wants to pick up credible information and than leaves again. People who repeatedly return to the discussion forum - to interact with others but also just to read the conversations - get to know more about the group itself [27] and about individual members. Also Ridings, Gefen and Arinze [1] mention that repeated interactions over time - together with the fact that contributions are publicly available - may allow trust to emerge.

Blomqvist states that in literature the dominant view prevails that trust is built up slowly. 'Trust needs close and repeated interaction to build up. Parties learn about each other's competences and intentions (Nooteboom, 2002) in repeated interactions [...]' [4]. Past experience, evidence and reputation play an important role when it comes to assigning trust. Trust is therefore highly dependent on the assumed knowledge of an individual, his reputation and his behavior in similar situations [35]. Keeping our context in mind, we can link this lack of experience to different user types. On the one hand you have people who regularly participate by adding a contribution or by frequently visiting the discussion forum. This group of people builds up a certain level of experience, both with specific group members as with the community itself. On the other hand there are people who less frequently visit the community in order to just pick up information. The latter category cannot fall back on a large amount of previous encounters with forum members and thus will have to find other ways to collect cues regarding reliability and competence. As stated before, we always interact on the basis of insecurity; we never fully know how trustworthy someone truly is [36]. This uncertainty is apparently stronger highlighted with new or less frequent forum users. 


\section{Typologies of Trust}

A typology of trust can be constructed based on the object of trust - in whom or what we trust - or on the stages within a trust relationship.

\subsection{Typology Based on Objects of Trust}

When focusing on the object of trust, a distinction can be made between general trust in people, trust in a specific person and trust with respect to an institution - or so called system trust. According to McKnight and Chervany [37] these three trust types are inextricably linked: the general level - tendency to trust - exerts influence on the contextual construction - system trust -, which in turn has an impact on interpersonal trust.

First of all, trust is strongly related to the personality of an individual [20] and can therefore be seen as a social-psychological construct. This general propensity / disposition to trust is often referred to in literature as a moral impulse, a capacity for trust or basic trust ( listed by [20] based on the work of Wilson, Hardin and Giddens) and 'generalized' trust [38]. It is a kind of basic level of trust, existing independently from specific contexts or people. Yet, due to the more sociological and communication studies perspective in this paper, we focus entirely on interpersonal and collective trust: members of and lurkers on discussion forums can either trust people or they can see the community itself as an object of trust.

Trust upon an interpersonal level refers to situational trust between two ore more individuals and is thus both context- and actor-specific: one trusts person A to do B within situation $\mathrm{C}$. When one is looking for advice or information on discussion forums, one often interacts with specific forum members by participating in the conversation or by reading through the conversation threads. As a lurker you do not have real contact - i.e. a conversation - with forum members but you might experience virtual personal trust; or an apparent intimacy with distant others [20]. Based on these conversations a reader or participant can decide to follow up the advice of a specific member in order to accomplish a certain goal. When dealing with interpersonal trust, the focus will be on individual characteristics of the trustee.

Literature states that people - due to the emergence of more temporary, airy and impersonal relationships - increasingly rely upon institutional trust; characterized by rules and structures in order to support the interpersonal aspect [39]. The development of online reputation systems is an example where one is trying to embed rules and structural guaranties within online communities. System trust however transcends the individual level. It is no longer about the personal properties of people but more about a belief in abstract principles and procedures [40]. Möllering [41] states that Giddens and Luhmann see institutional trust as trust based on visual control and performances. He stresses the importance of the entry point; where an actor makes an assessment of the complete system through the interaction with other actors. A positive first contact with a forum member will be extended to the entire community. Also McEvily, Weber, Bicchieri and Ho describe an evolution where trust in individual members would lead to the perception that the community can be trusted. Trust in a discussion forum as a 
collective could than be re-transferred to other individual members and could be used as a strategy when detailed information about specific members is missing or limited [14]. Group members are considered reliable because of their membership. Every individual contribution adds up to the reliability and trustworthiness of the community and visa versa; individual contributions are perceived to be credible because of association with the community [34]. Thus, a shared group identity will be an important trust antecedent for community members and readers of community content. An interesting concept that is rather close to the previous idea is the notion of 'institutional isomorphism' from DiMaggio and Powell (1983, as mentioned in [41]). Here, one unit is forced to conform to other units when they are operating in the same environment. In other words trust breeds trust or you trust because others trust as well. Within online discussion forums, this can be related to the fact that exchanges threads - are often aimed at the entire group and therefore publicly available for anyone to read. The idea of institutional isomorphism relies greatly on what Möllering [41] mentioned earlier in his article; actors place [institutional] trust because they take it for granted.

Combining these perceptions on interpersonal and system trust, we can expect that similarity on an interpersonal level will - especially at start of a new relationship - be largely based on individual socio-demographic characteristics. Homogeneity on a collective level is strongly linked to a shared group identity based on shared beliefs and interests [42]. 'People on the net have a greater tendency to develop feelings of closeness on the basis of shared interest rather than on the basis of shared social characteristics.' These feelings of closeness, described by Wellman and Gulia [42], will only develop through regular participation. Certain expectations considering the behavior of group members are being created due to membership within a certain group, which makes it easier to build trust [43]. Finally, feelings of togetherness and the sense of virtual community are not confined to active group members but can also be experienced by lurkers [44].

\subsection{Typology Based on Stages of Trust}

A division can also be made based on the stage of a relationship. Here initial and ongoing trust are considered important concepts.

In the work of McKnight and Chervany [37], initial trust is described as a phase in which people do not know each other: 'PPeople] have little solid, verifiable information about each other, and what they do know is not from first-hand, personal experience.' Here, people can use reputation, in-group categorization and stereotyping as antecedents or strategies to build initial trust.

Initial trust is also an important element when it comes to online discussion forums, since the achieved results will determine how a new user will deal with the forum and with the specific trustee in the future. Unlike long-term relationships of trust, which are rather resistant against small trust fractures, initial trust is rather fragile: it lacks feelings of affection so that once broken it will be difficult to build trust again [37]. Hardin [38] [45] refers to initial trust as 'as-if trust behavior'. As a new user or member trust is necessary when you are looking for information. Yet, you do not have 
anything to base trust upon, therefore you can choose to act as if you trust someone. If all goes well - i.e. when the trustee meets the expectations of the trustor - , this temporary situation eventually leads to real or ongoing trust. Looking at ongoing trust, both partners depart from a common interaction history. Thick [36] [46] or ongoing trust is based on knowledge and is build step by step by means of interactions over time. Here the key factor is having experience with the trustee [37].

Two other interesting concepts, which are highly consistent with the idea of stages within a trust relationship, are swift and slow trust. The concept of swift trust was introduced by Meyerson, Weick and Kramer [47] in response to an increase in project work within companies. According to the authors, this type of trust will be activated in a context where temporary groups with little or no prior history have to work together within a short period of time in order to achieve certain projects. Here, team members behave as if trust is already present (i.e. as-if trust) because there is insufficient time to go through the traditional stages of trust. Swift trust is therefore not based on experience with team members but rather on characteristics that allow people to be associated with certain categories or groups (category driven information [47]). Information about categories makes an identification based on stereotypical impressions possible, which in return leaves room for trust: 'Seeing oneself as similar to other people (or as part of a common group or category) provides a basis for assuming that these individuals have similar values and will therefore behave in similar and predictable ways.' [48].

The concept of swift trust leaves some space to reflect upon the formation of trust within online discussion forums. New and less-frequent members come to the forum without a common background on which they can base their trust. Moreover, trust signals are usually not directed at newcomers and group value is something difficult to grasp based on irregular, occasional and brief visits. Swift trust clearly corresponds to the idea of initial trust. Temporary groups - such as [new] forum users seeking urgent advice - can rely on a huge amount of information and expertise but they do not immediately know or do not have enough time to find out who knows what [47]. Of course initial trust and swift trust are not entirely the same. Swift trust originates from an organizational environment where people are mutually dependent, where they are obliged to work together, keeping a deadline in mind. Within discussion boards, other rules apply. Here people do not even have to have real interactions with each other. On the other hand, trust is also granted ex ante. ${ }^{2}$ When people - unfamiliar with the discussion platform and its members - are looking for information, they will need to develop trust in a quick manner, based on swift trust cues.

In line with initial trust, the emphasis is on in-group categorization and stereotyping. People will try to categorize the contributions of forum members based on small role indications such as a profile picture or even writing style (e.g. the use of jargon as an indication of expertise). When you are looking for some tips on parenting, you will pay more attention to the advice of a mother of three, than to the opinion of a man without children. When you want information about a painting job, you will tend to follow the

\footnotetext{
${ }^{2}$ Interdependence, interaction, task-oriented and a clear deadline are characteristics of the temporary organizational setting where trust will be granted ex ante. [47].
} 
advice of someone who just painted his house or from someone whose profession as a painter is reflected in his nickname. Seeing people as part of the same group as yourself can foster trust as well: 'this person is - just like myself - a member of a home improvement forum, so he must know something about renovations or at least he is in the same situation as I am'. The idea of in-group categorization is therefore twofold: people can be seen as members of a group of experts ['mums' or 'painters'] or as members of the same group ['they are renovating their house, just like me']. Also the idea that trust builds slowly - i.e. slow trust - fits perfectly with the concept of ongoing trust. Information about individual skills of forum members is collected through repeated social exchanges and regular visits to the discussion forum. Linking back to our objects of trust, we can assume that through these interactions people do not only develop interpersonal trust, they also learn how the online group deals with questions and comments, whether the group is helpful, how to pose questions and whether you can expect a clear and reliable answer. Both interpersonal and collective trust are built through use of and experience with the online community.

\section{$5 \quad$ Antecedents of Trust}

Within thriving online discussion boards there exists a huge amount of different users, each containing different levels of expertise. Therefore you cannot assign the same weight to every peer opinion. The degree to which a user will trust someone depends on a number of aspects. As a user you will try to estimate to what extent someone is credible, honest, accountable and benevolent in order to reduce feelings of risk. In order to grasp these dimensions of trust, people can use indications of expertise, reputation and identity. Important to notice is that these antecedents of trust do not take away the actual risk, it offers - as Luhmann [23] puts it - 'a spring board for the leap into uncertainty'. Identity can be seen as an overarching concept, including [indications of] reputation and expertise. Reputation - as a second layer - contains indications of expertise.

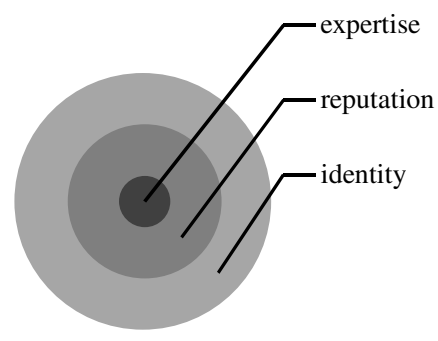

Fig. 1. Antecedents of trust 


\subsection{Identity}

'One reason for uncertainty in mediated environments is that, without visual and auditory social cues, people are not sure whether or not they can trust other people to be who they claim to be.' [51]

An online identity refers to the role forum members adopt when they make contributions online and to how users try to grasp the identity of others. Before people will trust someone, they will try to neutralize insecurity by making an assessment of the person. By exchanging [amongst other things] socio-demographic data, people can better understand each other's attitudes and beliefs, and predict behavior, causing reduced feelings of insecurity (see uncertainty reduction theory [49]). Sztompka [20] states that observed similar characteristics are important predictors of trust. Also: 'Having a known identity can be critical when assessing important information' [50]. In traditional face-to-face conversations people form impressions from each other's personality based on a wide range of both nonverbal and verbal cues. But what when people do not meet physically and what when you cannot fall back on a long-term relationship? Baym [51] argues that when people cannot link a physical appearance to a particular behavior, the authenticity of this behavior becomes less clear. People tend to trust others when they consider them as being equal. However, these similarities between trustor and trustee can - besides being physical or linked to sociodemographics - also be based on shared preferences, taste or lifestyle [8][29][34]. Walther [52] states that within a computer mediated communication environment, people idealize their interlocutors based on elements in messages that may indicate a minimal resemblance. According to Baym [51] small pieces of information are very important in an online environment that contains little cues. Even when these chunks of information where not distributed with the intention to release information about your personality. Besides unwittingly releasing cues about their identity; people of course also release certain aspects of their person in a highly controlled and socially desirable way [52].

People can seize upon two aspects to present themselves online or to grasp the identity of others. (1) Platform-dependent tools are instruments embedded in the online environment itself. The most fundamental tool, embedded in discussion boards, is a user profile containing aspects such as a nickname, an avatar, demographic information, a link to a personal website... According to Ma and Agarwal [53] persistent labeling - or the use of one label to present yourself - is important. By constantly joining a forum with the same user ID, other members can form an impression of the person. It allows community members to recognize and indicate central figures within the platform. A profile often also contains information about the frequency of use and your reputation as a contributor. This is what Ma and Agarwal [53] call deep profiling - or the digital organization of social information. Other items that could yield identity information are membership lists, rankings, 'who did what'functions and a possibility to browse the archive [53]. (2) Platform-independent tools also allow understanding of a person's identity but this insight is based on what can be abstracted from conversations. Language itself can ensure that you will be noticed online [51]. Besides the fact that it is much more pleasant to read witty contributions, 
language also allows you to tell something about yourself by means of self-disclosure. Self-disclosure or self-description is cited by both Baym [51] and Leary (1996, as mentioned in [53]) as an important way to construct identity online. By telling others something about yourself, you lose the label of newbie or stranger. It allows relationships to establish and to be maintained [51]. Not only does an act of selfdisclosure provides personal information which allows others to construct your identity; also trust in people who disclose personal information is generally higher [1].

Both tools mentioned can be seen as indications of a personal identity but they mainly give an initial impression of your discussion partner. The main way people actually gain insight in the identity of others is of course based on experience with members themselves.

\subsection{Reputation}

Several authors cite reputation as an important reference that allows to figure out the degree of integrity and the capacities of people and thus to build trust [20] [54] [55] [56] [57]. A reputation is 'an expectation about an agent's behavior based on information about or observations of its past behavior.' [55]. It is a record of past actions [20]. Through these past actions, you can try to make a prediction of future behavior. A reputation is often build upon direct observations and therefore rarely ahistorical (Good 1988:33 as mentioned in [20]). The longer you know someone, the more opportunities you have to assess this person's reliability and the greater the chance that a bond of trust will form [20] [54]. Yet, direct observations and personal experience are often problematic, since we regularly come in contract with people we do not know [that well]. Here people will switch to certain references like second-hand testimonies or achievements that demonstrate trust [20]. Also Scott and Johnson [58] talk about assigning a reputation based on personal experience, recommendations and association. Yet, the authors associate these elements with a typical community of place. Understanding reputation in online communities, can be done by looking at aggregated reputation scores [58]. Yet we do believe that - for example - sharing a picture online of a homemade cake, may lead others to think that you know a lot about baking. A similar example is when you share your profession as an electrician in your online user ID on a home improvement discussion forum. Although both individuals will not receive an overall reputation score, showing their achievements can nevertheless contribute to their reputation.

On online discussion platforms, a reputation can be formed on the basis of direct observations. The opinion of a specific member becomes highly important when previous discussions with this person gave proof of expertise. Somewhere in the past, you have asked a question on the forum and you followed the advice of a specific member with success as a result. However, the idea of direct observation is somewhat more complex in a textual community since conversations remain publicly available. When someone publicly demonstrates trust - e.g. by saying he is going to try out the advice - and this trust becomes subsequently confirmed - e.g. by thanking the forum 
member for the good advice -, other members can see this display of trust, which allows the reader of this conversation to decide to proceed with trusting behavior himself. This entire idea fits strongly with the following quote from Sztompka [20]: 'Being visibly trusted by some may be an argument for others to grand trust too.'

Forum users also have the possibility to derive a reputation based on indirect observations. On the one hand, one can use references from other forum members. For example when during a forum discussion a member refers to another member as being an expert in a certain domain. Another type of reference includes what we have explained earlier with the example of the homemade cake. Showing a picture of something you have made or talking about your experience with certain tasks indirectly shows your expertise/experience within a certain domain and can help to shape your online reputation. New forum users - those who cannot fall back on their own experiences with other members - can also rely on online reputation mechanisms. Some online communities provide their members with explicit information about other users based on rankings, ratings, collaborative filtering and peer-based systems [56]. In this way they attempt to provide members with a less anonymous image.

\subsection{Expertise}

Expertise is also an important reason for people to assign trust [8][13][34][59][60]. Expertise indicates whether a particular source / user is competent or not: Does this person have the necessary knowledge to judge the situation in a correct way or to give proper advice? It is the extent to which a source is regarded as being capable to formulate valid statements [60]. According to Mackiewicz [61] expertise gives people a reason to trust. She sees it as a warranty people can use to make an assessment. Sharing your own experience with using a consumer good or with the performance of a particular task, placing a picture on a discussion forum as proof, using technical or sitespecific language or disseminating difficult to find information... These are all examples that can lead to people being granted with the status of an expert. They give insight in the fact whether a person has the necessary skills and knowledge to know what he is talking about. According to Mackiewicz [61] forum members can express expertise by using specialized terminology or by making an explicit claim of expertise. This explicit claim of expertise can be made by telling about your experience with a certain product, a service or a task through a forum post. Yet we believe that less explicit portrayals of expertise can be important as well; for example showing of your crafts via a picture can be the ultimate proof that you know what you are talking about. A claim of expertise can also be made on the basis of a relevant role: 'reviewers construct [...] an identity for themselves that included a role particularly relevant to the product.' [61]. According to Mackiewicz [61], roles can be based upon people's experience from a hobby or employment in a profession. They can also be based upon the fact that the member had a formal training or has done a lot of research - which the author calls an instant expert - and upon second hand experiences - the forum member does not talk about his own experiences but about his connection with another person who has relevant experience. 


\section{Conclusion}

Throughout this paper, an attempt was made to gain insight in the way people build trust within a semi-anonymous online environment such as online discussion boards. These surroundings are typically characterized by the exchange of mainly written messages between people who often do not know each other physically/offline. Important to mention is the absence of any reputation system, which makes computing with or for trust impossible. The fact that we are dealing with a cue-poor environment where a large part of the population cannot fall back on previous, intensive experiences with forum members, makes the construction of trust less easy to understand. Grasping the identity of the person who's message you are reading seems to become a rather difficult task.

In order to form a better understanding of trust, we identified six central concepts, essential when formulating a definition: interdependence, expectations, risk, insecurity, action and vulnerability. When you decide to follow up the advice of a forum member, you take up a dependent position with respect to this member and this on the assumption that following up his advice would lead to a desired result. Yet by acting upon someone's advice, you take a certain risk. You never fully know whether the person is adequate to formulate advise, which makes that you find yourself in a rather vulnerable position. Furthermore we discussed a typology of trust based on the object of trust - e.g. interpersonal trust aimed at a specific forum member versus system trust directed at the discussion platform as a whole - and based on the stages within a relationship - e.g. initial or swift trust experienced by new members and people who less frequently visit the forum in order to gather information versus ongoing or slow trust experienced by loyal members.

Looking back on this paper it appears that user types runs like a thread throughout the entire work. Interpersonal trust seems especially important within the initial trust stage where 'new' members try to make an evaluation of the knowledge, skills and veracity of other members. These users cannot count on experiences within the community and will therefore have to make an assessment of trustworthiness based on the individual characteristics people render in their messages. In order to gain an insight into the identity, the reputation or the level of expertise of specific members, one can depend on in-group categorization and stereotyping. One can pick up small role indications from user IDs or elements of self-disclose in the messages of members. System trust seems to be more reserved for loyal users, people who have developed an ongoing [trust] relationship with the community an its members. Here we are not longer dealing with personal features but it is more a general idea that you can count on the community to answer your questions with appropriate advice. Trust is being created through membership. Based on exchanges over time, users form an idea about the extent to which members share the same beliefs and interests.

Still some work has to be done to make both user types and trust antecedents more explicit. An empirical study, based on interviews with forum members and an analysis of forum conversations, would yield a more detailed user typology instead of a mere contradiction between new and old members or information seekers and social contact seekers. It would also help to get a deeper understanding of possible trust antecedents. It is not enough to say that people could use cues in user IDs or messages. In stead the 
focus should be on what they actually use and whether they do this rationally. An analysis of forum conversations would also allow us to see how people come to consensus.

\section{References}

1. Ridings, C.M., Gefen, D., Arinze, B.: Some Antecedents and Effects of Trust in Virtual Communities. Journal of Strategic Information Systems 11(3), 271-295 (2002)

2. Hertzum, M., Andersen, H.H.K., Andersen, V., Hansen, C.B.: Trust in Information Sources: Seeking Information from People, Documents and Virtual Agents. Interacting with Computers 14(5), 575-599 (2002)

3. Ljung, A., Wahlforss, E.: People, Profiles \& Trust: On Interpersonal Trust in WebMediated Social Spaces (2008), http: / / trustmojo.com/book/ (viewed January 2011)

4. Bijlsma-Frankema, K., Klein Woolthuis, R. (eds.): Trust Under Pressure: Trust and Trust Building in Uncertain Circumstances, pp. 1-16. Edward Elgar Publishing Limited, Cheltenham (2005)

5. Blanchard, A.L., Welbourne, J.L., Boughton, M.D.: A Model of Online Trust. The Mediating Role of Norms and Sense of Virtual Community. Information, Communication and Society 14(1), 76-106 (2011)

6. Gefen, D.: E-commerce: The Role of Familiarity and Trust. Omega the International Journal of Management Science 28(6), 725-737 (2000)

7. McKnight, D.H., Choudhury, V., Kacmar, C.: Developing and Validating Trust Measures for E-commerce. Information Systems Research 13(3), 334-359 (2002)

8. Smith, D., Menon, S., Sivakumar, K.: Online Peer and Editorial Recommendations: Trust and Choice in Virtual Markets. Journal of Interactive Marketing 19(3), 15-37 (2005)

9. Dwyer, C., Hiltz, S.R., Passerini, K.: Trust and Privacy Concern Within Social Networking Sites: A Comparison of Facebook and MySpace. In: Proceedings of the 13th Americas Conference on Information Systems, paper 339. Curran Associates Inc., Keystone (2007)

10. Jarvenpaa, S.L., Shaw, T.R., Staples, S.D.: Toward Contextualized Theories of Trust: The Role of Trust in Global Virtual Teams. Information Systems Research 15(3), 250-267 (2004)

11. Sillence, E., Briggs, P., Harris, P., Fishwick, L.: A Framework for Understanding Trust Factors in Web Based Health Advice. International Journal of Human Computer Studies 64(8), 697-713 (2006)

12. Bos, N.D., Olson, J.S., Gergle, D., Olson, G.M., Wright, Z.: Effects of Four ComputerMediated Channels on Trust Development. In: Proceedings of the Conference on Human Factors in Computing Systems, pp. 135-140. ACM Press, New York (2002)

13. Corritore, C.L., Kracher, B., Wiedenbeck, S.: On-line Trust: Concepts, Evolving Themes, a Model. International Journal of Human-Computer Studies 58(6), 737-758 (2003)

14. McEvily, B., Weber, R.A., Bicchieri, C., Ho, V.T.: Can Groups Be Trusted? An Experimental Study of Trust in Collective Entities. In: Bachmann, R., Zaheer, A. (eds.) Handbook of Trust Research, pp. 52-67. Edward Elgar, Cheltenham (2006)

15. Rousseau, D.M., Sitkin, S.B., Burt, R.S., Camerer, C.: Not So Different After All: A Cross-Discipline View of Trust. Academy of Management Review 23(3), 393-404 (1998)

16. Banerjee, S., Bowie, N.E., Pavone, C.: An Ethical Analysis of the Trust Relationship. In: Bachmann, R., Zaheer, A. (eds.) Handbook of Trust Research, pp. 303-317. Edward Elgar, Cheltenham (2006) 
17. Barber, B.: The Logic and Limits of Trust. Rutgers University Press, New Brunswick (1983)

18. Luhmann, N.: Familiarity, Confidence, Trust: Problems \& Alternatives. In: Gambetta, D. (ed.) Trust: Making and Breaking Cooperative Relations, pp. 94-107. Basil Blackwell Ltd., Oxford (1988)

19. Gambetta, D.: Can We Trust Trust? In: Gambetta, D. (ed.) Trust: Making and Breaking Cooperative Relations, pp. 213-237. Basil Blackwell Ltd., Oxford (1988)

20. Sztompka, P.: Trust: A Sociological Theory. Cambridge University Press, Cambridge (1999)

21. Castaldo, S.: Trust in Market Relationships. Edward Elgar Publishing, UK (2007)

22. Mayer, R.C., Davis, J.H., Schoorman, D.F.: An Integrative Model of Organizational Trust. Academy of Management Review 20(3), 709-734 (1995)

23. Luhmann, N.: Trust and Power. Wiley, Chichester (1979)

24. Polanyi, M.: Personal Knowledge Towards a Post-Critical Philosophy. Routledge and Kegan Paul Ltd., London (1958)

25. Rosenberg, B.C.: The Our House DIY Club: Amateurs, Leisure Knowledge and Lifestyle Media. International Journal of Cultural Studies 14(2), 173-190 (2011)

26. Mondal, A., Kitsuregawa, M.: Privacy, Security and Trust in P2P Environments: A Perspective. In: Proceedings of the 17th International Workshop on Database and Expert Systems Applications, pp. 682-686. IEEE Computer Society, CA (2006)

27. Fisher, D.: Studying Social Information Spaces. In: Lueg, C., Fisher, D. (eds.) From Usenet to CoWebs. Interacting with social information spaces, pp. 3-19. Springer (2003)

28. Metzger, M.J.: Making Sense of Credibility on the Web: Models for Evaluating Online Information and Recommendations for Future Research. Journal of the American Society for Information Science and Technology 58(13), 2078-2091 (2007)

29. Golbeck, J.: Introduction to Computing with Social Trust. In: Golbeck, J. (ed.) Computing with Social Trust. Human-Computer Interaction Series. Springer-Verlag London Limited, London (2009)

30. Boyd, J.: The Rhetorical Construction of Trust Online. Communication Theory 13(4), 392-410 (2003)

31. Erickson, T., Kellogg, W.A.: Social Translucence: Using Minimalist Visualisations of Social activity to Support Collective Interaction. In: Hook, K., Benyon, D., Munro, A.J. (eds.) Designing Information Spaces: The Social Navigation Approach, pp. 17-41. Springer, London (2003)

32. Riegelsberger, J., Sasse, A.M., McCarthy, J.D.: The Researcher's Dilemma: Evaluating Trust in Computer-Mediated Communication. Human-Computer Studies 58(6), 759-781 (2003)

33. Johnson, C.A.: Choosing People: The Role of Social Capital in Information Seeking Behavior. Information Research 10(1), paper 201 (2004),

http: / / informationr. net/ir/10-1/paper201.html (viewed January 2013)

34. Brown, J., Broderick, A.J., Lee, N.: Word of Mouth Communication Within Online Communities: Conceptualizing the Online Social Network. Journal of Interactive Marketing 21(3), 2-20 (2007)

35. Busacca, B.G., Castaldo, S.: Trust as Market-Based Resource: Economic Value, Antecedents and Consequences. In: Bijlsma-Frankema, K., Klein Woolthuis, R. (eds.) Trust Under Pressure: Empirical Investigations of Trust and Trust Building in Uncertain Circumstances, pp. 148-169. Edward Elgar, London (2005) 
36. Kramer, R.M.: Trust as Situated Condition: an Ecological Perspective on Trust Decisions. In: Bachmann, R., Zaheer, A. (eds.) Handbook of Trust Research, pp. 68-86. Edward Elgar, Cheltenham (2006)

37. McKnight, D.H., Chervany, N.L.: Reflections on an Initial Trust-Building Model. In: Bachmann, R., Zaheer, A. (eds.) Handbook of Trust Research, pp. 29-51. Edward Elgar, Cheltenham (2006)

38. Hardin, R.: Trust and Trustworthiness. Russell Sage Foundation, New York (2002)

39. Van De Ven, A.H., Smith Ring, P.: Relying on Trust in Cooperative Inter-Organizational Relationships. In: Bachmann, R., Zaheer, A. (eds.) Handbook of Trust Research, pp. 144-164. Edward Elgar, Cheltenham (2006)

40. Sydow, J.: How Can Systems Trust Systems? A Structuration Perspective on TrustBuilding in Inter-Organizational Relations. In: Bachmann, R., Zaheer, A. (eds.) Handbook of Trust Research, pp. 377-392. Edward Elgar, Cheltenham (2006)

41. Möllering, G.: Rational, Institutional and Active Trust: Just Do It!? In: Bijlsma-Frankema, K., Klein Woolthuis, R. (eds.) Trust Under Pressure: Empirical Investigations of Trust and Trust Building in Uncertain Circumstances, pp. 17-36. Edward Elgar Publishing Limited, Cheltenham (2005)

42. Wellman, B., Gulia, M.: Net Surfers Don't Ride Alone: Virtual Communities as Communities. In: Kollock, P., Smith, M.A. (eds.) Communities in Cyberspace, pp. 163-190. Westview, Boulder (1997)

43. Gargiulo, M., Ertug, G.: The Dark Side of Trust. In: Bachmann, R., Zaheer, A. (eds.) Handbook of Trust Research, pp. 165-186. Edward Elgar, Cheltenham (2006)

44. Nonnecke, B., Preece, J.: Silent Participants: Getting to Know Lurkers Better. In: Lueg, C., Fisher, D. (eds.) From Usenet to CoWebs. Interacting with Social Information Spaces, pp. 110-132. Springer (2003)

45. Möllering, G.: Trust, Institutions, Agency: Towards a Neoinstitutional Theory of Trust. In: Bachmann, R., Zaheer, A. (eds.) Handbook of Trust Research, pp. 355-376. Edward Elgar, Cheltenham (2006)

46. Williams, B.: Formal Structures and Social Reality. In: Gambetta, D. (ed.) Trust: Making and Breaking Cooperative Relations, pp. 3-13. Basil Blackwell Ltd, Oxford (1988)

47. Meyerson, D., Weick, K.E., Kramer, R.M.: Swift Trust and Temporary Groups. In: Kramer, R.M., Tyler, T.R. (eds.) Trust in Organizations: Frontiers of Theory and Research, pp. 166-195. Sage Publications, Thousand Oaks (1996)

48. Adams, B.D., Waldherr, S., Sartori, J., Thomson, M.: Swift Trust in Distributed Ad Hoc Teams. Research report Defense Research and Development, Toronto, Canada (2007), http: / /pubs.rddc-drdc.gc.ca/BASIS/pcandid/www/engpub/ DDW?W\%3DAUTHOR+\%3D+\%27Sartori $\% 2 \mathrm{C}+\mathrm{J} . \% 27 \% 26 \mathrm{M} \div 3 \mathrm{D} 3 \% 26 \mathrm{~K} \% 3 \mathrm{D} 528962 \%$ 26U\%3D1 (viewed July 2011)

49. Berger, C.R., Calabrese, R.J.: Some Explorations in Initial Interaction and Beyond: Toward a Developmental Theory of Communication. Human Communication Research 1(2), 99-112 (1975)

50. Jessen, J., Jorgensen, A.H.: Aggregated Trustworthiness: Redefining Online Credibility Through Social Validation. First Monday 17(1-2) (2012),

http: / / www. firstmonday.org/htbin/cgiwrap/ bin/ojs/index.php/fm/article/view/3731/3132 (viewed June 2012)

51. Baym, N.K.: Personal Connections in the Digital Age. Polity Press, Cambridge (2010)

52. Walther, J.B.: Selective Self-Presentation in Computer-Mediated Communication: Hyperpersonal Dimensions of Technology, Language, and Cognition. Computers in Human Behavior 23(3), 2538-2557 (2007) 
53. Ma, M., Agarwal, R.: Through a Glass Darkly: Information Technology Design, Identity verification and Knowledge Contribution in Online Communities. Information Systems Research 18(1), 42-67 (2007)

54. Dasgupta, P.: Trust as a Commodity. In: Gambetta, D. (ed.) Trust: Making and Breaking Cooperative Relations, pp. 49-72. Basil Blackwell Ltd., Oxford (1988)

55. Alfarez, A.R., Hailes, S.: A Distributed Trust Model. In: Proceedings of the 1997 Workshop on New Security Paradigms, pp. 48-60. ACM, New York (1997)

56. Jensen, C., Davis, J., Farnham, S.: Finding Others Online: Reputation Systems for Social Online Spaces. In: Proceedings of the Conference on Human Factors in Computing Systems, pp. 447-454. ACM Press, New York (2002)

57. Koutrouli, E., Tsalgatidou, A.: Reputation-Based Trust Systems for P2P Applications: Design Issues and Comparison Framework. In: Fischer-Hübner, S., Furnell, S., Lambrinoudakis, C. (eds.) TrustBus 2006. LNCS, vol. 4083, pp. 152-161. Springer, Heidelberg (2006)

58. Scott, J.K., Johnson, T.G.: Bowling Alone But Online Together: Social Capital in E-communities. Journal of the Community Development Society 36(1), 9-27 (2005)

59. Bailey, B.P., Gurak, L.J., Konstan, J.A.: Trust in Cyberspace. In: Ratner, J. (ed.) Human Factors and Web Development, pp. 311-322. Lawrence Erlbaum Associates, Mahwah (2002)

60. Willemsen, L.M., Neijens, P.C., Bronner, F.E., Koning, A.: Credibility Assessments of Online Product Reviewers: The Effects of Perceived Expertise and Perceived Trustworthiness. Paper Presented at the Annual Conference of the Netherlands School of Communication Research, Enschede, The Netherlands (2011)

61. Mackiewicz, J.: Assertions of Expertise in Online Product Reviews. Journal of Business and Technical Communication 24(1), 3-28 (2010) 